\title{
Tackling the motivation to monitor: success and sustainability of a participatory monitoring program
}

\author{
Navinder J. Singh ${ }^{1}$, Kjell Danell, Lars Edenius and Göran Ericsson
}

\begin{abstract}
Monitoring of species and their ecosystem attributes is a fundamental requirement in applied ecology and conservation. However, landscape scale monitoring requires an immense effort and commitment, especially when species have a wide distribution or are migratory in nature. Participatory monitoring, whereby local communities are engaged, is increasingly being proposed to address landscape scale monitoring. Its implementation is met with many challenges related to finances, motivation of the local people, lack of trained manpower, and nondirect legal use of the species in question. It is of interest to determine what makes a participatory monitoring program interesting for locals to ensure their long term engagement. Using the unique 26-year program of hunters' observations of moose (Alces alces) in Sweden as a case study, we present the evolution of this highly successful participatory monitoring program and show that tackling the motivation to monitor, early involvement of local NGOs, social activities revolving around use of the resource, the biology and economic value of the species, and technical and practical aspects related to the monitoring, together create a successful participatory monitoring program. When users benefit directly from the resource, participate in conservation/ management decision making, socialize with other participants, and get rewards for their commitment and effective monitoring, participatory monitoring schemes can then become rewarding and sustainable.
\end{abstract}

Key Words: biology of the species; citizen science; cost-effectiveness; efficiency; hunter observations; migratory species; moose; social activities; ungulates

\section{INTRODUCTION}

Monitoring biodiversity in space and time is fundamental to understanding the ecology and conservation of ecosystems and their components (Yoccoz et al. 2001). Monitoring species abundance, in particular, and distributions at landscape scales present challenges to conservation and management because of the high costs of data collection over large areas and the variation in detectability at multiple scales (Jones 2011). At landscape scales, i.e., areas covering thousands of kilometres and with multiple habitat types, when species are mobile or migratory, fluctuate in populations, and occur in clusters, monitoring costs and efforts are relatively steep (Jones 2011, Singh and MilnerGulland 2011a). Over large landscapes and when species are widely distributed, participatory monitoring, which also falls under the 'citizen science' umbrella, although citizen science may also engage people outside the local communities, is proposed to be a cost effective way of monitoring (Danielsen et al. 2000, 2005a, $b, 2010$, Sutherland 2003, Hockley et al. 2005, Silvertown 2009). This linking of monitoring to local people is believed to not only lower costs, but to empower local people in multiple dimensions and hence enhance prospects for monitoring to be sustainable in the long term, be it for conservation or management (Danielsen et al. 2000, Lawrence 2006, Rist et al. 2010, Constantino et al. 2012). Can we learn from the existing monitoring programs of harvested migratory species, especially when global conservation initiatives, such as the Convention on Migratory Species, actively promote conservation through sustainable use (CMS 2012) and landscape and ecosystem based conservation?

Reviews of the accomplishments of citizen science projects (Silvertown 2009, Dickinson et al. 2012), which share the same base as participatory monitoring programs, have revealed that such projects have greatly contributed to the detection of range shifts and reproductive phenology in migratory species induced by climate change (Root et al. 2003) along with similar distributional and phenological shifts in plant species (Crimmins et al. 2009). Such projects have also assisted in finding rare species, tracking movements and population trends, and increasing overall engagement of people in scientific research (Losey et al. 2007, Schmeller et al. 2009, Gallo and Waitt 2011). Many scientific agencies and institutions are encouraging the use of participants' critical thinking skills in their projects as well as increasing interindividual interactions between participants and professionals (Dickinson et al. 2012). For participants, such projects have yielded development of pride, self-esteem, freedom of choice, women's rights, education, increased social capital, and participation in decision making and governance over natural resources (Lawrence 2006).

In spite of the accomplishments, the main difficulties that surround the effective development of participatory monitoring programs, especially for the economically important species distributed over large scales, are: lack of direct legal harvesting of species in many countries, disputed timing of harvest, land ownership, lack of trust between harvesters and government agencies, complicated data collection protocols, accuracy and the reliability of the data collected, and sustainability in the long term (Danielsen et al. 2005a, Whitebread 2008, Dickinson et al. 2012). Dickinson et al. (2012) reviewed multiple citizen science projects and concluded that getting people to contribute was the most effort-intensive task. Sustaining such projects requires strategic collaborations and partnerships. Most literature promoting participatory monitoring discusses the high value of the approach for conservation and management, but little is usually discussed on how to make such a program interesting for the locals to ensure their long term engagement (Lawrence 2006, Constantino et al. 2012). Certainly, there are biological aspects and economic value of the target resource, but social, psychological, political, 
practical, and technical aspects of the monitoring are equally pivotal (Danielsen et al. 2005b, DeCaro and Stokes 2008). These include the motivation to monitor; interest in how and when the monitoring is to be carried out, in a team or not; whether there are any side activities or recreational values alongside monitoring; if individual achievements count and whether there are rewards for the participants; and what level of participants' technical skill and education is required (Hockley et al. 2005, Constantino et al. 2012).

To address the challenges of getting people to contribute and sustain participatory monitoring projects in the long term (Dickinson et al. 2012), we present a case study on the evolution of a landscape-scale, participatory monitoring program in Sweden (spread over the entire country), its working details, and the ingredients that make it successful and sustainable in the long term. The main objective hence is to discuss what makes a participatory monitoring program interesting for people. We predict that if the method motivates participants, then the participation of users and their reported observations should increase and/or remain stable over time. On another level, if successful, its replication to other species should also be an indicator of its success. The study is primarily an opinion and hence has not been designed and conducted as a standard scientific or social study. We do not aim to develop any framework but mainly discuss the features of an existing system, which can be used as a model.

\section{Evolution of the moose monitoring system}

The moose (Alces alces) in Scandinavia is a hunted species, distributed across the entire region. Its population fluctuates in numbers and is partially migratory (Ball et al. 2001, Singh et al. 2012). The Swedish moose population was close to extinction in early 1900's caused by overhunting. Because of conservation and management actions, moose have successfully recovered to a sustainably managed game species at the national level, i.e, a nonthreatened, viable population with wide distribution (Fig. 1). This recovery is a result of a series of measures, which included shortening of the hunting season, banning of passive and effective hunting methods, i.e., pitfall traps, dogs, snares, 'moose police' protecting moose from poachers, killing of large carnivores, usage of harvest statistics, age and sex specific harvests, and finally the change from a top-down to a bottom-up control of moose management. This 100-year period of change resulted in an impressive recovery of moose populations in Sweden, i.e., from a few hundred to around 300,000 (after the hunting season). The moose population reached its peak around 1980 with half a million moose. During this time, the collection of harvest statistics became a large administrative task as the moose populations expanded in distribution and number. The available survey methods for national and regional level monitoring, i.e., aerial census, pellet counts, and different indeces of browsing pressure on forest tree species, were expensive, logistically demanding or insufficiently evaluated in their accuracy and precision. Hunters and foresters, because of damages suffered to valuable timber trees, also began calling for a better monitoring system of moose populations. The need for a cheaper, alternative monitoring system became obvious, and hence a participatory monitoring program was initiated. Around 1980, a regional manager at the Swedish Association of Hunting and Wildlife Management (SAWHM) began testing an observation-based monitoring program from Norway called "Sett Elg"/observed moose, which reported the number of moose seen. From 1985 onwards (Fig. 1), this moose monitoring system was adopted and made voluntary across Sweden.

Fig. 1. Annual time series of harvest of moose (Alces alces) in Sweden from 1900 to 2010 and the major events and initiatives that led to the adoption and evolution of the current hunters' observations method.

\section{Number of Felled Moose from 1900 - 2010}

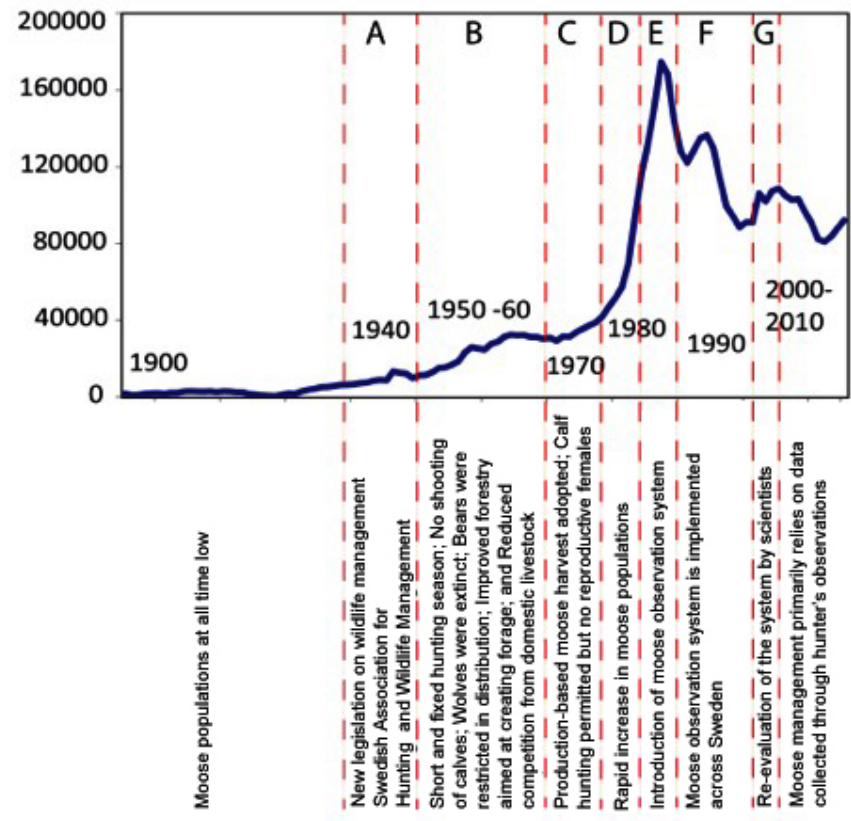

During the period 1990-1995 (Fig. 1), the hunters slowly started to lose confidence in the moose observation program because it had not been tested enough, scientifically. The same mistrust debate occurred in Norway at that time. In 1996-1997, the Swedish and Norwegian authorities launched a collaborative scientific review, which evaluated the moose observation system for its precision and accuracy (Engen et al. 1998) and recommended that the moose observation program should continue because the results provided by the index followed the true population development and reproduction pattern (Engen et al. 1998, Ericsson and Wallin 1999, Sylvén 2000, Solberg et al. 2005, Månsson et al. 2011). These recommendations restored the trust of the hunters in the program, and from 2000 onward (Fig. 1), the Swedish moose management relied mainly on the voluntary observations by hunters and theirs teams. The scientific credibility of the program was further evaluated by Ericsson and Wallin (1999) who found that a change in observation index also reflected a change in population size with $80 \%$ reliability. The ability to detect change declined as the population density exceeded one moose per $\mathrm{km}^{2}$, and the observations could not be compared across management units; these were identified as weaknesses of the method. These limitations were primarily attributed to the local differences in the life history, distribution, and movement of moose populations, as well as habitat type. Sylvén (2000) 
further suggested that the size of the study affected the probability to detect changes in population size because the magnitude of moose movements varies across the country (Singh et al. 2012). The hunters' observation method works better for large areas ( $>$ $50000 \mathrm{ha}$ ), and the effectiveness to detect change declines as the size of the area decreases. This is mostly because large areas can contain entire migratory ranges of animals as opposed to smaller areas, which may only contain one seasonal range or migratory route (Singh et al. 2012).

\section{Description of the moose monitoring system, 'Älgobs'}

The moose monitoring system ('Älgobs' or 'moose observations') in Sweden is managed and run by hunters (Ericsson and Wallin 1999). It involves the systematic use of observations to estimate changes in population sizes and composition. Hunters carry out the observations voluntarily. It is implemented across Sweden and moose observations in the first seven hunting days of the first hunting month (September in the north and October in the south) are recorded. Every hunting team records the number of hunters each day, number of hunting days, and the daily observations. They follow clear instructions on how to count observations in special cases, e.g., if several hunters stand together and observe the same individual, or if hunters observe from their watchtowers (www.viltdata.se). The hunters provide observations per hunting hour, an index that is used to detect changes in moose population sizes over time. For identifying changes in populations, the first seven hunting days are compared between years. Observations per man-hour is used as a measure of the population density. Number of calves per cow and calves per hundred females are used as the reproductive measure. A minimum 5000 hours are required to be able to capture the real change in population between days or years at the county level (Ericsson and Wallin 1999, Solberg et al. 2005). The hunters compile daily reports and then submit a final report to the "Viltdata" website. The reporting is done on a standardized form obtained at the webpage or distributed to hunting teams.

\section{METHODS}

To understand the characteristics of the moose monitoring system, we reviewed the existing social science and ecological literature, conducted semistructured interviews with two managers, who coordinated the monitoring at the national level, at the Swedish Association of Hunting and Wildlife Management head office (SAHWM or 'Svenska Jägareförbundet), and acquired hunter observation data for the two northern counties and their communes to identify trends in hunters' participation and observations over time. At the administrative level, a county is made up of multiple communes. The latter was done to measure success and sustainability. The existing literature was searched in Google Scholar, Web of Science, using the following keywords: hunter's observation, settälg, Älgobs, and moose monitoring in Sweden, Norway, and Finland.

\section{RESULTS}

\section{Trends in hunter participation and reported observations}

An analysis of the trends in hunters' participation and the total number of hunters' observations reported in two selected counties revealed that the participation has increased in one and remained relatively stable in another since 1997 (Fig. 2a). The numbers of reported observations have remained relatively stable in one and have slightly decreased in another county (Fig. 2b). However, the $R^{2}$ values do not show a significant change in either (Fig. 2).

Fig. 2. Temporal trends in (a) the number of hunters registered within the two counties of Västerbotten and Norrbotten in Sweden, and (b) the total observations of moose reported in these counties. The fitted line is based on a linear regression model.

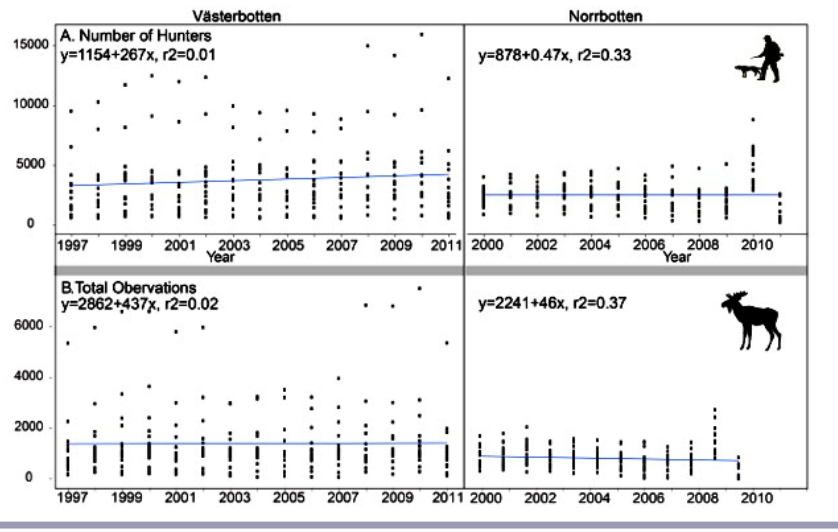

\section{The motivation to observe}

In Sweden, roughly $50 \%$ of the forest lands are owned by private land owners, and $40 \%$ are owned by companies, either private or state "owned." This means that many hunters hunt on their own land or land belonging to the family and are therefore interested and motivated to collect information on their areas. The rest of the land in Sweden is managed by the church. All Swedes have the right to free passage on land 'Allemansrätten,' which means that every citizen is free to move around and use the natural resources, which are not used commercially. This freedom brings a sense of common ownership of the land when compared to countries in which trespassing on private land is strictly prohibited. 'Allemansrätten' gives a person the right to access, walk, cycle, ride, ski, and camp on any land, except private gardens, the immediate vicinity of a house, and cultivated land. Restrictions apply for nature reserves and other protected areas. It also gives the right to pick wild flowers, mushrooms, and berries, provided one knows they are not legally protected, but prohibits hunting and fishing. The landowners have hunting rights on their land, regardless of its size. The landowners may lease out their land to individual hunters and hunting associations.

Hunting has a wide acceptance among the Swedes; $4 \%$ of the adults hunt and $70 \%$ consume game meat on a regular basis. Every year, about a third $(80,000-10,0000)$ of the moose population is harvested (Kindberg 2010). The estimated value of moose hunting is about 1.4 billion Euro per year or 0.4 Euro per day per person (Mattson et al. 2008). There are about 270,000 registered hunters in Sweden (www.jagareforbundet.se), with most of them organized into hunting teams of about 8-15 hunters on average. To qualify as a hunter, both theoretical as well as practical training and examination are needed, since 1985 onward. In total, each year the hunters spend about 1,875,000 days or 4.5 million hours observing moose (Ericsson and Wallin 1999). All hunters pay an annual hunting fee to the Swedish government. Moose hunting generally occurs during a 70-day period, starting in early 
September in the north, and in mid-October in the south. However, the timing can be variable across the country.

\section{Societal needs and economic value}

Moose hunting generates extensive revenue, which is a strong rationale for people to directly engage in its monitoring and management (Mattson et al. 2008). Stakeholders from forestry and agriculture suffer from damages to forest trees and crops by the moose, and because of the large economic value of these damages, moose monitoring is needed. The figures on estimated damage to forestry at $\sim 150$ million Euros (Swedish Forest Agency, http://www.skogsstyrelsen.se/) and traffic accidents at $\sim 100$ million Euros per year (Seiler 2005) are equally significant. In Sweden there are $\sim 5000$ moose-related road accidents per year (Seiler 2005, Neumann et al. 2012). To minimize the damages and accidents, costly measures are taken, e.g., building fences and wildlife passages. A large increase in moose and other ungulate populations has an impact on biodiversity and ecosystem processes (Persson et al. 2000), which is a subject of concern for government and nature conservation agencies (Edenius et al. 2002, Seiler 2005). Therefore, the size of the moose population is of general interest to society.

\section{Biology of the species}

The large size $(\sim 300-800 \mathrm{~kg})$ and high abundance $(>500,000$ animals or $\sim 1$ moose $/ \mathrm{km}^{2}$ ) of moose in Sweden make them easy to detect with the naked eye, or through signs such as browse marks, trampling, bark stripping, or pellets. These signs require little effort to monitor for hunters. Moose have direct and indirect effects on the smaller vertebrates and invertebrates that exist in the boreal ecosystem (Danell et al. 1985, Persson et al. 2000, Mathisen et al. 2010). Hence, their biological value is of great significance to the ecology of the whole system. A high reproductive rate and survival also enable their rapid recovery and make them a suitable species for harvesting (Ericsson et al. 2001).

\section{Social aspects of the hunting community}

Hunting teams are often composed of members who may live anywhere in the country. As in most hunting areas, hunters own the land they hunt on; they therefore maintain a strong interest in knowing the resources they own. Hence, self-monitoring provides a sense of trust and ownership of the data they collect. Often, the same hunters hunt for many years on the same land. The sheer numbers, distribution, and the efficiency of the hunters is remarkable and unparalleled elsewhere. Sweden also has strict laws on carrying guns and promotes ethical hunting. Each hunter is required to follow the rules.

It is not only the hunting process and the desire for wild meat that motivate the hunters to monitor, but also the social events and activities associated with hunting, which equally enhance their participation. Since 1938, SAWHM, through its local chapters, has been organizing seminars, evening classes, and providing the necessary infrastructure for activities related to hunting, e.g., shooting ranges for training and slaughter houses. The opening of the moose hunting season is an important social event for many hunters who no longer reside in rural areas. Hunters pay an annual membership fee and organize periodic meetings, during and outside the hunt, and usually have a dinner following the hunt after opening week (personal communication with hunters). Target shooting is another popular social sport for many hunters, which they actively engage in. About $80 \%$ of hunters in Sweden have dogs, and training dogs for hunting gives them a sense of pride when a dog is able to successfully locate an animal.

A rapid, easily accessible and relatively straightforward reporting system is an advantage, which also yields rapid feedback from the management. Hunters trust the data if they have been active in its collection. Another important feature of the system is its transparency, which makes it highly appealing to the volunteers and other stakeholders, a key requirement for success identified by Danielsen et al. (2005a). Hunters can upload their reports directly to the servers and explore previous year's data, as well as view data from other counties and hunting teams on the Viltdata website.

The SAWHM publishes a periodic journal, Svensk Jakt http:// www.jagareforbundet.se/svenskjakt/, with 11 issues per year, dedicated to hunters interested in wildlife, guns, dogs, nature, and the outdoors. It is widely read by hunters because it provides a national platform for hunting-related issues. Some hunters also participate in nature photography competitions in which their pictures are rewarded. More recently, free mobile phone applications ("Viltappen" and "WeHunt") have been developed, which keep the hunters in the loop with the latest news, hunting regulations, coordination during hunting, management initiatives, and other information on wildlife and nature. The SAWHM has also developed a Geographic Information System (GIS) platform so that the collected data can be better linked to geographical positions and maps.

Despite the pleasures of hunting, the interest of hunters in different types of monitoring, e.g., pellet counts, aerial surveys, varies depending upon the method followed. For example, conducting pellet counts only provides the benefit of being outdoors in the fresh air and is less popular than helicopter counts, which give prestige to the hunters who are selected as observers. It also increases their interactions with the government and the management agencies at both local and national levels.

\section{Technical and practical aspects}

Hunters' observations come at a rather low cost to the government and large land owners, such as forest companies (Månsson et al. 2011). It encourages social responsibility, is simple, less bureaucratic, managed by hunters, and leads to sustainable management of the resource. Scientists outline the program, follow it continuously, and analyze the data for quality control (Sylvén 2000). Training is also organized on the observation system, for entering data, and for exploring past trends, using a user friendly system. Hunters are required to report the hunting team ID, the parish, the commune, the county, the day of the hunt, the number of hunters, the number of hours spent hunting, the number of animals of each category seen, i.e., bulls, cows, cows with calves, and cows without calves, calves, and the number of animals shot in each category. A form is then filled with this information, and then uploaded to the web. A well-developed, web-based system and a strong hunters' organization enables effective and quick decision making, allows discussion on hunting-related issues, and assists in identifying research needs. The ability of the monitoring system to detect trends within areas has been carefully evaluated and its strengths and weaknesses are explicitly communicated (Ericsson and Wallin 1999, Sylvén 2000, 
Solberg et al. 2005). The participants have the information available at hand in the management system, as well as on the forms and the portal where their data is submitted.

\section{Scientific credibility and cost effectiveness}

A number of scientific investigations through time have evaluated the applicability of this method and its power to detect changes, its cost effectiveness, relevance at different scales, and its efficiency and reporting. The method is inexpensive and cost effective. Månsson et al. (2011) compared three survey methods in a small area and estimated that the total costs of the aerial count was about 27,000 Euros, for the pellet counts it cost 8400 Euros, and for hunters' observations it cost 1600 Euros. Similarly, Rönnegård et al. (2008) evaluated four methods: aerial counts, hunters' observations, pellet group counts, and cohort analysis, and they showed that the hunter's observations could be used to estimate long term trends even in moderately sized areas $\left(\sim 500 \mathrm{~km}^{2}\right)$.

\section{Application to other species}

The popularity of the hunters' observations method has led SAHWM and scientists to replicate the method with other species in Sweden. After the scientific evaluation of the method in 1997, it was extended to the population monitoring of large carnivores, such as bears (Ursus arctos), lynx (Lynx lynx), wolf (Canis lupus), and wolverine (Gulo gulo; Kindberg et al. 2009). For bears, Kindberg et al. (2009) found that the index from hunters' observations correctly reflected bear distribution, and the index related linearly to the independent density estimates at the scale of local management units (about $1000-2000 \mathrm{~km}^{2}$ ). The message that emerges then is that the method can be used for common and abundant, as well as elusive species of high conservation value (Kindberg et al. 2009).

\section{DISCUSSION}

We have outlined the moose observations system and its features and shown that a rapid increase in population and distribution of moose prompted the need to develop a landscape scale monitoring program. We also presented a number of social factors that motivate the hunters' participation in the program. The economic and biological value of moose for both hunters, foresters, and traffic collisions management are strong motivators for these stakeholders to engage in moose monitoring. In addition, the right of access to land, largely private ownership of land driving a sense of awareness about the resources on their property, social part of the hunt, earning rewards for better reporting and monitoring, and events associated with hunting are also vital social factors, which motivate the hunters to participate. The SAWHM also plays a pivotal role in coordinating with the hunting community, keeping it motivated through social events and technological innovations, and ensuring that the observation system remains functional.

As a measure of success and sustainability, first and foremost, the continuation of the system, after its scientific evaluation in 1997, is a good indicator that the system has been well received. It is ongoing to this day. A stable trend in the number of hunters participating in the system, as well as stability, or increase in the total observations reported, provides evidence that the hunters continue to collect and report data consistently (Fig. 2a, b). A slight decline, although not significant, in total observations and number of hunters in Norrbotten can be attributed to a general emigration of people from the area because of economic reasons (E. Ölund, unpublished manuscript).

Early engagement of a local NGO (SAWHM) and its local chapters in educating the hunters and organizing and maintaining the system has played a significant part in keeping the system running. The system covers all the counties in Sweden, i.e., the entire nation. Månsson et al. (2011) provided evidence on the low cost for the government and large landowners. The system is simple in its reporting, which is a significant factor to keep people engaged, as outlined by several other researchers (Luzar et al. 2011, Parsons et al. 2011). Development of mobile phone applications and a dedicated GIS indicates a continuing interest among the hunting community to keep developing and improving the monitoring program, to increase the precision and accuracy in observations, and also enhance communication among the hunters. A successful replication of the monitoring system with other species, such as bears, is another indicator of its success and sustainability.

A study by Luzar et al. (2011) from Amazonia reported that the motivation of the local people to want to monitor and participate in a participatory monitoring program should be identified during the early stages of the development of the program. In the case of moose observations, the motivation was identified quite early, because hunters and foresters realized the impact of increasing moose populations and distributions. Luzar et al. (2011) also suggested that preliminary research findings of the data collected by participants should be communicated to the participants. The moose data is coordinated by SAWHM and is regularly communicated to the hunters. Although the data collection by hunters is a valuable effort and speaks in favor of the hunters, if hunters call for lower hunting quotas, other stakeholders such as forestry companies and the transportation sector may come into conflict depending upon the population index estimates obtained from the data. In such cases, conflicts may arise and recommended management actions may be rejected. As reported in Namibia and Amazonia by Constantino et al. (2012), communities occasionally rejected conservation management actions supported by monitoring data in favor of political decisions concerning communities' developmental interests. A major challenge, identified by many studies, is the maintenance of a participatory monitoring program over time, especially if it is vulnerable to funding uncertainty (Constantino et al. 2012, Dickinson et al. 2012). Although in the Swedish case, funding is not a limiting factor, because the system is purely voluntary. Nevertheless, the low cost of the monitoring program and the fact that the decision-making power lies at the local level, empowers the hunters. Danielsen et al. (2005a) have suggested previously that systems that promote empowerment are expected to last longer. The moose monitoring program has now lasted for 26 years. The strength of this case study is that it shows that a participatory monitoring program involves multiple years of hard work and continuous engagement with people. This is an important message for conservation projects currently engaged in designing and introducing participatory monitoring program throughout the globe. Similarly, for citizen science programs, which are founded on people's engagement, there are lessons to be learned from this study to make these schemes sustainable in the long term and to maintain the reliability of data (Dickinson et al. 2012). 
Despite the advantages discussed above, we do recognize that there are aspects that are unique to Sweden: (1) free right of access to land and private land ownership; (2) predators are strictly controlled in their distribution and population size, which indirectly affects the hunting management and allows for a better correction for predator-related mortality; (3) finances are often available for experimenting with the management decisions and research, both by the Swedish Environmental Protection Agency and by SAWHM; (4) most hunters are often highly educated (Lindberg 2010), use internet, and women are increasingly participating in hunting (Heberlein 2000, Heberlein et al. 2008); (5) the hunting community is large and highly organized with management power at the local level. Nonetheless, these aspects do not allow for an easy establishment of cause and effect relationships in the participatory monitoring program and its success. This is a possible avenue for future research, as ours is the first effort to bring these aspects together in the context of participatory monitoring.

For the replication of the moose monitoring system with other species or systems, a number of factors need consideration. The biology, ethical/cultural value, and the economic importance of the resource in question; the level of interest from the local community to manage and monitor it over the long term; the detection probability; and the best indicators of changes in populations are all crucial. The reporting system should be kept simple and preferably, a central coordination agency could be established, which would actively communicate with participants, the scientific community, and management. The other emphasis would be to make participation more fun as in the case of moose hunting. Organizing local chapters of NGOs, which can directly engage people in social events, popular media, high-tech applications, as well as establishing a participants' group in which all participants could be members, can be highly useful initiatives. Engaging locals in scientific surveys, decision-making meetings, research seminars, and rewarding and encouraging their participation can also yield greater benefits in terms of their increased interest. These suggestions are highly useful for other systems in which participatory monitoring programs are in their early stages of development or are being planned, and in which strong legislations regarding hunting are already in place. Often, protected areas, community management areas, and wildlife management (hunting) areas in developing countries are short on money for monitoring, because often it is much more important to invest in development or food security (Singh and MilnerGulland 2011 b, Kinahan and Bunnefeld 2012). Thus finances are key, but it is often not recognized that the monitoring objectives can actually be achieved, i.e., detecting a population trend, measuring abundance accurately, measuring biodiversity, with the resources and expertise at hand. The cost-effective, participatory monitoring is a way ahead to address such problems. The main message that emerged from our study, which has been ignored by earlier literature on participatory monitoring, is to emphasize the motivation to monitor and not just focus on mechanisms that reduce costs of conservation. Monitoring of biodiversity and ecosystem services is a top priority in today's world and participatory monitoring methods are vital in accomplishing monitoring, especially in an uncertain and dynamic situation (Jones 2011, Sommerville et al. 2011, Williams et al. 2012).
Responses to this article can be read online at: http://www.ecologyandsociety.org/issues/responses. $\mathrm{php} / 6665$

\section{Acknowledgments:}

NJS was funded by the thematic program in Wildlife and Forestry at the Swedish University of Agricultural Sciences. Thanks to Jonas Kindberg for providing the hunters observation data. We thank Finn Danielsen, Michael K. Poulsen, Andrew Allen, Jean-Michel Roberge, Evgenia Markovskaya, Nils Bunnefeld, and four anonymous reviewers for valuable comments on the manuscript.

\section{LITERATURE CITED}

Ball, J. P., C. Nordengren, and K. Wallin. 2001. Partial migration by large ungulates: characteristics of seasonal moose Alces alces ranges in northern Sweden. Wildlife Biology 7:39-47.

Convention on Migratory Species (CMS). 2012. Convention on the Conservation of Migratory Species. Convention on Migratory Species, Bonn, Germany. http://www.cms.int/en/node/3916

Constantino, P. A. L., H. S. A. Carlos, E. E. Ramalho, L. Rostant, C. Marinelli, D. Teles, S. F. Fonseca-Junior, R. B. Fernandes, and J. Valsecchi. 2012. Empowering local people through communitybased resource monitoring: a comparison between Brazil and Namibia. Ecology and Society 17(4): 22. http://dx.doi. org/10.5751/ES-05164-170422

Crimmins, T. M., M. A. Crimmins, and C. D. Bertelsen. 2009. Flowering range changes across an elevation gradient in response to warming summer temperatures. Global Change Biology 15:1141-1152. http://dx.doi.org/10.1111/j.1365-2486.2008.01831. $\underline{\mathrm{X}}$

Danell, K., K. Huss-Danell, and R. Bergström. 1985. Interactions between browsing moose and two species of birch in Sweden. Ecology 66:1867-1878. http://dx.doi.org/10.2307/2937382

Danielsen, F., D. S. Balete, M. K. Poulsen, M. Enghoff, C. M. Nozawa, and A. E. Jensen. 2000. A simple system for monitoring biodiversity in protected areas of a developing country. Biodiversity and Conservation 9:1671-1705. http://dx.doi. org/10.1023/A:1026505324342

Danielsen, F., N. D. Burgess, and A. Balmford. 2005a. Monitoring matters: examining the potential of locally-based approaches. Biodiversity and Conservation 14:2507-2542. http://dx.doi. org/10.1007/s10531-005-8375-0

Danielsen, F., N. D. Burgess, P. M. Jensen, and K. Pirhofer-Walzl. 2010. Environmental monitoring: the scale and speed of implementation varies according to the degree of peoples involvement. Journal of Applied Ecology 47:1166-1168 http://dx. doi.org/10.1111/j.1365-2664.2010.01874.X

Danielsen, F., A. E. Jensen, P. A. Alviola, D. S. Balete, M. Mendoza, A. Tagtag, C. Custodio, and M. Enghoff. 2005b. Does monitoring matter? A quantitative assessment of management decisions from locally-based monitoring of protected areas. Biodiversity and Conservation 14:2633-2652. http://dx.doi. org/10.1007/s10531-005-8392-Z 
DeCaro, D., and M. Stokes. 2008, Social-psychological principles of community-based conservation and conservancy motivation: attaining goals within an autonomy-supportive environment. Conservation Biology 22:1443-1451. http://dx.doi.org/10.1111/ j.1523-1739.2008.00996.x

Dickinson, J. L., J. Shirk, D. Bonter, R. Bonney, R. L. Crain, J. Martin, T. Phillips, and K. Purcell. 2012. The current state of citizen science as a tool for ecological research and public engagement. Frontiers in Ecology and the Environment 10:291-297. http://dx.doi.org/10.1890/110236

Edenius, L., M. Bergman, G. Ericsson, and K. Danell. 2002. The role of moose as a disturbance factor in managed boreal forests. Silva Fennica 36:57-67. http://dx.doi.org/10.14214/sf.550

Engen, S., G. Ericsson, K. Jerstad, B.-E. Sæther, K. Wallin, and T. Willebrand. 1998. Sett elg og Cersim som verktøy i elgforvaltningen. Direktoratet for Naturforvaltning og Svenska Jägareförbundet, Öster malma, Sweden. (In Swedish).

Ericsson, G., and K. Wallin. 1999. Hunter observations as an index of moose Alces alces population parameters. Wildlife Biology 5:177-185.

Ericsson, G., K. Wallin, J. P. Ball, and M. Broberg. 2001. Agerelated reproductive effort and senescence in free-ranging moose Alces alces. Ecology 82:1613-1620.

Gallo, T., and D. Waitt. 2011. Creating a successful citizen science model to detect and report invasive species. BioScience 61:459-465. http://dx.doi.org/10.1525/bio.2011.61.6.8

Heberlein, T. A. 2000. The gun, the dog and thermos. Culture and hunting in Sweden and the United States. Sweden and America $13: 24-29$

Heberlein, T. A., B. Serup, and G. Ericsson. 2008. Female hunting participation in North America and Europe. Human Dimensions of Wildlife 13:443-458. http://dx.doi.org/10.1080/10871200802294265

Hockley, N. J., J. P. G. Jones, F. B. Andriahajaina, A. Manica, E. H. Ranambitsoa, and J. A. Randriamboahary. 2005. When should communities and conservationists monitor exploited resources? Biodiversity and Conservation 14:2795-2806. http://dx.doi. org/10.1007/s10531-005-8416-8

Jones, J. P. G. 2011. Monitoring species abundance and distribution at the landscape scale. Journal of Applied Ecology 48:9-13. http://dx.doi.org/10.1111/j.1365-2664.2010.01917.x

Kinahan, A. A., and N. Bunnefeld. 2012. Effective and cost efficiency of monitoring mountain nyala in the Bale Mountains National Park. Endangered Species Research 18:105-114. http:// dx.doi.org/10.3354/esr00438

Kindberg, J. 2010. Monitoring and management of the Swedish brown bear Ursus arctos population. Dissertation. Swedish University of Agricultural Sciences, Umeå, Sweden.

Kindberg, J., G. Ericsson, and J. E. Swenson. 2009. Monitoring rare or elusive large mammals using effort-corrected voluntary observers. Biological Conservation 142:159-165. http://dx.doi. org/10.1016/j.biocon.2008.10.009
Lawrence, A. 2006. 'No personal motive?' Volunteers, biodiversity, and the false dichotomies of participation. Ethics, Place and Environment 9(3):279-298. http://dx.doi. org/10.1080/13668790600893319

Lindberg, D.-E. 2010. Hunter demography, trends and correlates of hunting participation in Sweden. Thesis. Swedish University of Agricultural Sciences, Umeå, Sweden. [online] URL: http:// stud.epsilon.slu.se/957/

Losey, J. E., J. E. Perlman, and E. R. Hoebeke. 2007. Citizen scientist rediscovers rare nine-spotted lady beetle, Coccinella novemnotata, in eastern North America. Journal of Insect Conservation 11:415-417 http://dx.doi.org/10.1007/s10841-007-9077-6

Luzar, J. B., K. M. Silvius, H. Overman, S. T. Giery, J. N. Read, and J. M. V. Fragoso. 2011. Large-scale environmental monitoring by Indigenous peoples. BioScience 61:771-781. http://dx.doi. org/10.1525/bio.2011.61.10.7

Mathisen, K. M., F. Buhtz, K. Danell, R. Bergström, C. Skarpe, O. Suominen, and I.-L. Persson. 2010. Moose density and habitat productivity affects reproduction, growth and species composition in field layer vegetation. Journal of Vegetation Science 21:705-716. http://dx.doi.org/10.1111/j.1654-1103.2010.01180. $\underline{\mathrm{x}}$

Mattson, L., M. Boman, G. Ericsson, A. Paulrud, T. Latila, B. Kriström, and R. Brännlund. 2008. Welfare foundations for efficient management of wildlife and fish resources for recreational use in Sweden. Pages 169-181 in B. Lovelock, editor. Tourism and the consumption of wildlife. Routledge, New York, New York, USA.

Månsson, J., C. E. Hauser, H. Andrén, and H. P. Possingham. 2011 Survey method choice for wildlife management: the case of moose Alces alces in Sweden. Wildlife Biology 17:176-190. http:// dx.doi.org/10.2981/10-052

Neumann, W., G. Ericsson, H. Dettki, N. Bunnefeld, N. S. Keuler, D. P. Helmers, and V. C. Radeloff. 2012. Difference in spatiotemporal patterns of wildlife road-crossings and wildlifevehicle collisions. Biological Conservation 145:70-78. http://dx. doi.org/10.1016/j.biocon.2011.10.011

Parsons, J., R. Lukyanenko, and Y. Wiersma. 2011. Easier citizen science is better. Nature 471:37. http://dx.doi.org/10.1038/471037a

Persson, I.-L., K. Danell, and R. Bergström. 2000. Disturbance by large herbivores in boreal forests with special reference to moose. Annales Zoologici Fennici 37:251-263.

Rist, J., E. J. Milner-Gulland, G. Cowlishaw, and M. Rowcliffe. 2010. Hunter reporting of catch per unit effort as a monitoring tool in a bushmeat-harvesting system. Conservation Biology 24:489-499. http://dx.doi.org/10.1111/j.1523-1739.2010.01470.x

Root, T. L., J. T. Price, K. R. Hall, S. H. Schneider, C. Rosenzweig, and J. L. Pounds. 2003. Fingerprints of global warming on wild animals and plants. Nature 421:57-60. http://dx.doi.org/10.1038/ $\underline{\text { nature } 01333}$

Rönnegård, L., H. Sand, H. Andrén, J. Månsson, and Å. Pehrson. 2008. Evaluation of four methods used to estimate population density of moose Alces alces. Wildlife Biology 14:358-371. http:// dx.doi.org/10.2981/0909-6396(2008)14[358:EOFMUT]2.0.CO;2 
Schmeller, D. S., P.-Y. Henry, R. Julliard, B. Gruber, J. Clobert, F. Dziock, S. Lengyel, P. Nowicki, E. Déri, E. Budrys, T. Kull, K. Tali, B. Bauch, J. Settele, C. van Swaay, A. Kobler, V. Babij, E. Papastergiadou, and K. Henle. 2009. Advantages of volunteerbased biodiversity monitoring in Europe. Conservation biology 23:307-316. http://dx.doi.org/10.1111/j.1523-1739.2008.01125.x

Seiler, A. 2005. Predicting locations of moose-vehicle collisions in Sweden. Journal of Applied Ecology 42:371-382. http://dx.doi. org/10.1111/j.1365-2664.2005.01013.X

Silvertown, J. 2009. A new dawn of citizen science. Trends in Ecology and Evolution 24:467-471. http://dx.doi.org/10.1016/j. $\underline{\text { tree.2009.03.017 }}$

Singh, N. J., L. Börger, H. Dettki, N. Bunnefeld, and G. Ericsson. 2012. From migration to nomadism: movement variability in a northern ungulate across its latitudinal range. Ecological Applications 22(7): 2007-2020. http://dx.doi.org/10.1890/12-0245.1

Singh, N. J., and E. J. Milner-Gulland. 2011a. Conserving a moving target: planning protection for a migratory species as its distribution changes. Journal of Applied Ecology 48:35-46 http:// dx.doi.org/10.1111/j.1365-2664.2010.01905.x

Singh, N. J., and E. J. Milner-Gulland. 2011b. Monitoring ungulates in Central Asia: current constraints and future potentials. Oryx 45:38-49. http://dx.doi.org/10.1017/S0030605310000839

Solberg, E. J., V. Grøtan, C. M. Rolandsen, H. Brøseth, and S. Brainerd. 2005. Change-in-sex ratio as an estimator of population size for Norwegian moose Alces alces. Wildlife Biology 11:163-172. http://dx.doi.org/10.2981/0909-6396(2005)11[163:CRAAEO] 2.0.CO;2

Sommerville, M. M., E. J. Milner-Gulland, and J. P. G. Jones. 2011. The challenge of monitoring biodiversity in payment for environmental service interventions. Biological Conservation 144:2832-2841. http://dx.doi.org/10.1016/j.biocon.2011.07.036

Sutherland, W. J. 2003. Ecological census techniques: a handbook. Cambridge University Press, Cambridge, U.K.

Sylvén, S. 2000. Effect of scale on hunter moose Alces alces observation rate. Wildlife Biology 6:157-165.

Williams, S. J., J. P. G. Jones, C. Clubbe, and J. M. Gibbons. 2012. Training programmes can change behaviour and encourage the cultivation of over-harvested plant species. PLoS One 7:e33012. http://dx.doi.org/10.1371/journal.pone.0033012

Whitebread, E. 2008. Evaluating the potential for participatory monitoring of saiga antelope by local villagers in Kalmykia, Russia. Thesis. Imperial College, London. U.K. [online] URL: http://www.academia.edu/2588387/Evaluating the potential_fo$\underline{\mathrm{r} \text { participatory monitoring of saiga antelope by local villag- }}$ ers in Kalmykia Russia

Yoccoz, N. G., J. D. Nichols, and T. Boulinier. 2001. Monitoring of biological diversity in space and time. Trends in Ecology and Evolution 16:446-453. http://dx.doi.org/10.1016/S0169-5347(01) 02205-4 